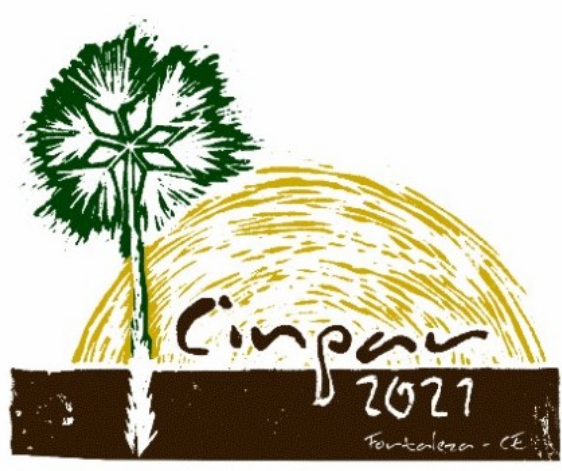

XVII Congresso Internacional sobre Patologia e

Reabilitação das Construções

XVII Congreso Internacional sobre Patología y Rehabilitación de las Construcciones

XVII International Conference on Pathology and Constructions Rehabilitation

FORTALEZA (Brasil), 3 a 5 de junho de 2021

https://doi.org/10.4322/CINPAR.2021.078

\title{
Influência das escolhas projetuais sobre o processo de degradação em fachadas
}

\section{Influence of design choices on the facade degradation process}

Larissa Carvalho de SOUSA ${ }^{1}$, Jéssica Siqueira de SOUZA ${ }^{2}$, Alan Victor DIAS ${ }^{3}$, Afonso R. Garcez de AZEVEDO ${ }^{4}$

\author{
${ }^{1}$ Universidade de Brasília, Brasília, Brasil, larissacarsousa@gmail.com \\ ${ }^{2}$ Universidade de Brasília, Brasília, Brasil, jss.siqueira@gmail.com \\ ${ }^{3}$ Universidade de Brasília, Brasília, Brasil, alanvictor.dias@gmail.com \\ ${ }^{4}$ Universidade Estadual do NorteFluminense, Campos dos Goytacazes, Brasil, afonso.garcez91@gmail.com
}

\begin{abstract}
Resumo: A degradação é um processo natural devido ao envelhecimento dos edifícios. A fachada das edificações sofre a influência da degradação e por estar mais exposta aos agentes climáticos exteriores do que outros elementos apresenta grande vulnerabilidade ao fenômeno de degradação. Este artigo aborda sobre a influência das características e escolhas projetuais sobre o processo de degradação do sistema de revestimento cerâmico em fachadas de edifícios localizados em Brasília, Brasil. A partir de um extenso banco de dados que contempla informações de áreas degradadas e características dos edifícios, a análise do indicador de degradação denominado Fator de Danos e a obtenção de curvas de probabilidade de danos tornou-se possível. Os resultados possibilitarama melhorcompreençãodo impacto das características projetuais no processo de degradação e consequentemente na vida útil das fachadas. Assim, esta pesquisa subsidia informações para que no futuro sejam elaboradas melhores estratégias de manutenção e conservação de desempenho de fachadas.
\end{abstract}

Palavras-chave: Durabilidade; Vida útil; Degradação; Fachada; Características projetuais.

\begin{abstract}
Degradation is a natural process due to the aging of buildings. The buildings' facade goes through the impact of degradation and because it is more exposed to external climatic agents than other elements, it is highly vulnerable to the phenomenon of degradation. This article approaches the influence of design features and choices on the degradation process of the ceramic cladding system on building facades in Brasília. From an extensive database that includes information on degraded areas and features of buildings, the analysis of the degradation indicator called Damage Factor and obtaining probability of damage curves is possible. The results allow to better understand the impact of the design characteristics on the degradation process and, consequently, on the service life of the facades. Thus, this research subsidizes information so that in the future better strategies for maintaining and conserving facade performance are developed.
\end{abstract}

Keywords: Durability; Lifespan; Degradation; Facade; Design features.

\section{Introdução}

A degradação é um processo natural de deterioração intrínseco a qualquer material devido ao envelhecimento. Sendo assim, a fachada do edifício não é isenta a esse fenômeno, pelo contrário, sendo mais vulneravél devido a sua alta exposição. Conforme a norma brasileira NBR 15575-4 (2013), a fachada é considerada como um sistema de vedação vertical externo. Este sistema tem função estética, bem como 
função técnica. Dentre as funções da fachada, destaca-se a função de proteção da edificação contra os agentes de degradação, além de garantir conforto aos usuários.

O desempenho do sistema deve ser constantemente avaliado, a fim de garantir a função de proteção da fachada (NBR 15575-1, 2013). Todos aqueles agentes atuantes sobre as fachadas e que podem comprometer o desempenho do sistema de vedação são considerados agentes de degradação, tal como agentes físicos, químicos, mecânicos e biológicos (ISO 15686-1, 2011).

A existência de manifestações patologicas indicam o não atendimento ao desempenho, afeta a durabilidade, a função estética da fachada e, consequentemente, desvalorização da edificação (Gaspar e de Brito, 2008). Desta forma, a compreensão do fenômeno de degradação atinge à questões econômicas e sustentáveis. Entretanto, a degradação é um fenômeno complexo, pois depende de diversos fatores. As características projetuais, a orientação da fachada, a execução, o uso e a manutenção também são alguns dos fatores que podem indiretamente influenciar na sua degradação. A combinação destes fatores com os agentes de degradação resultam no surgimento de manifestações patológicas no sistema de revestimento (Bauer et al.,2020). A complexidade e dificuldade de quantificação, compreensão e avaliação deste fenômeno ressalta a relevância deste estudo dentro do contexto da Engenharia Civil.

Diante do exposto, a fim de contribuir com os estudos relacionados a degradação e durabilidade de fachadas, esta pesquisa tem como objetivo avaliar a influência das escolhas projetuais sobre o processo de degradação em fachadas de edifícios residenciais localizados em Brasília, Brasil. Por meio da utilização do indicador de degradação denominado Fator de Danos, a degradação foiquantificada para as anomalias mais comuns em sistemas de revestimento e por conseguinte a frequência das anomalia em função de características projetuais é analisada. Este estudo traz conhecimentos que permitem a elaboração de planos eficazes de manutenção e recomendações projetuais, que podem contribuir com a redução de custos ao longo da vida útil das edificações.

\section{Degradação de fachadas}

Diversos pesquisadores (Bauer et al., 2015; Silva et al.,2014)afirmam que as anomalias que frequentemente acometem sistemas de revestimento cerâmico de fachada são o descolamento cerâmico (Figura01a), fissuração (Figura 01b), falha de rejunte (Figura 01c) e surgimento de eflorescência (Figura 01d).

a)

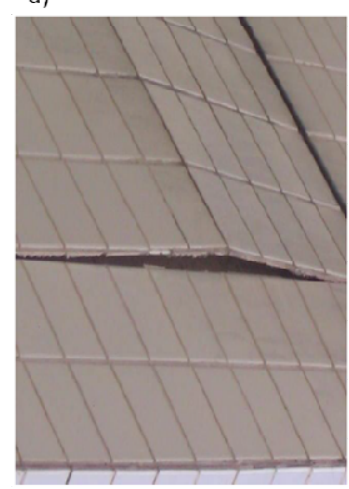

b)

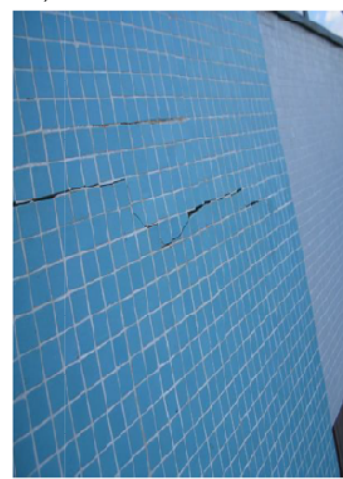

c)

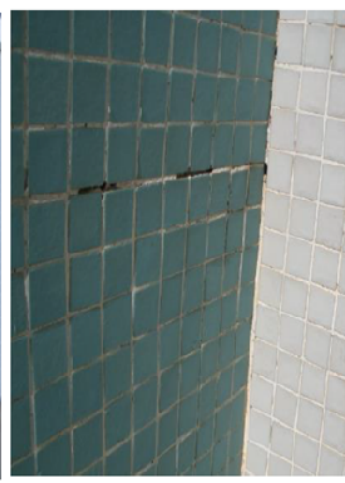

d)

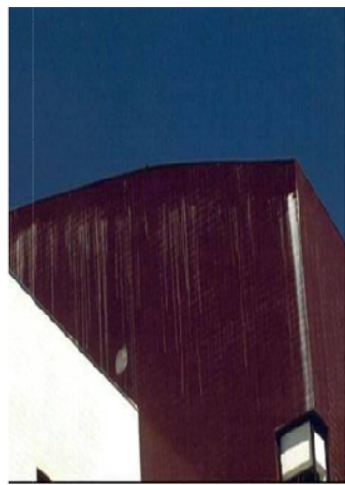

Figura 1 - Anomalias frequentes em revestimento cerâmico de fachada: (a) Descolamento cerâmico, (b) Fissuração, (c) Falha de rejunte e (d) Eflorescência (Silva, 2014)

As anomalias que prejudicam drasticamente o desempenho das fachadas são o descolamento cerâmico e a fissuração. Alguns pesquisadores (Bordalo et al., 2010; Flores-Colen et al., 2010) afirmam que o descolamento cerâmico tem como principais causas a incompactibilidade das propriedades, falhas de resistência, execução e assentamento, uso incorreto dos materiais constituintes do sistemade revestimento, movimentação excessiva do edifício, expansão das cerâmicas, erro na especificação e execução, o excesso tempo entre preparo e assentamento da argamassacolante e falta de manuntenção. A existência de descolamento cerâmico afeta a condição estética das edificações e causa graves riscos de 
acidentes a pedrestes. Além de afetar o desempenho das edificações e outros elementos internos. A fissuração ocorre frequentemente devido a variação de temperatura ao longo do ano que provoca a contração e dilatação dos materiais, fazendo assim com que surja tensões gerando fissuras (Bauer et al., 2015).

As anomalias de falha de rejunte e efloresência apresentam menor impacto que a fissuração e o descolamento cerâmico. Entretanto estas anomalias também afetam o desempenho do sistema de revestimento cerâmico. A falha de rejunte consiste principalmente na ocorrência de fissuras e/ou desprendimento do rejunte. $O$ surgimento desta anomalias permite o ingresso de água da chuva para o interior do sistema (Souza et al., 2018). Estas surgem devido a definição inadequada da espessura utilizada, no preparo e aplicação inadequada do material,erros de projetos e de aplicações inadequadas.O surgimento de eflorescência está relacionado ao deposito de cristais provenientes de sais que estavam dissolvidos na água e que, após sua evaporação, formam manchas brancas na superfície da fachada. Além de a eflorescência afetar a aparência da superfícies fachadas, estas indicam presença de umidade no sistema e possíveis problemas de infiltração que causam danos aos usuários.

\section{Indicador de degradação}

O fenômeno de degradação pode ser avaliado a partir da mensuração quantitativa das anomalias existentes em um sistema construtivo. O Método de Mensuração de Degradação (MMD) foi desenvolvido por pesquisadores a fim de avaliar a vida útil de sistemas de revestimento cerâmico de fachadas em edificios residenciais (Silva, 2014; Souza, 2019; Bauer et al., 2020). Dentre os indicadores de degradação adotados por este método, cita-se o Fator de Danos (FD). Este indicador reflete a extensão de degradação da fachada e pode ser calculado conforme equação 01.

$$
F D=\frac{\sum A_{d(n)}}{A_{t}}
$$

Em que FD é o indicador de degradação Fator de Danos, $A_{d(n)}$ é a área de determinada anomalia (n) em $m^{2} e$ $A_{t}$ é a área total da amostra de fachada em $\mathrm{m}^{2}$.

A frequência de ocorrência das anomalias pode ser obtida pelo indicador de degradação FD. Através do Fator de Danos é possível também quantificar a degradação de cada anomalia para as orientações de fachada (Norte Sul, Leste e Oeste). Desta forma, a metodologia desenvolvida nesta pesquisa consiste na elaboração de curvas de probabilidade que melhor representam a ocorrência das anomalias para cada orientação por meio de histogramas e testes de aderência promovendo o ajuste de curvas probabilísticas. Com o auxilio do software EasyFit, os testes de ajuste de curvas adotados foram Kolmogorov-Smirnov, Anderson-Darlin e Qui-Quadrado. O objeto de estudo contempla informações de inspeções de fachadas referente a mais de 35 edifícios residenciais com idades que variam de 5 a 48 anos.

\section{Análise de resultados}

\subsection{Probabilidade de anomalias}

O Fator de Danos é um índice que aponta a frequência de ocorrência dos danos. Assim torna-se possível que essa frequência seja relacionada com a probabilidade de ocorrência de anomalias. Os histogramas do Fator de Danos para as fachadas analisadas em relação as anomalias de Descolamento Cerâmico, Fissuração, Falha de Rejunte e Eflorescência foram obtidos. Para realizar o ajuste dos histogramas por uma função de distribuição de probabilidade, foram testadas as curvas de probabilidade de Lognormal, Gumbel, Weibull, Normal e Exponencial. Considerando quealguns pesquisadoresutilizaramestas curvas para avaliar a probabilidade de degradação em fachadas, optou-se por utilizar as mesmas curvas (Silva et al., 2015). Os histogramas e as curvas de probabildade das anomalias consideradas nesta pesquisa estão apresentadas na Figura 2. 


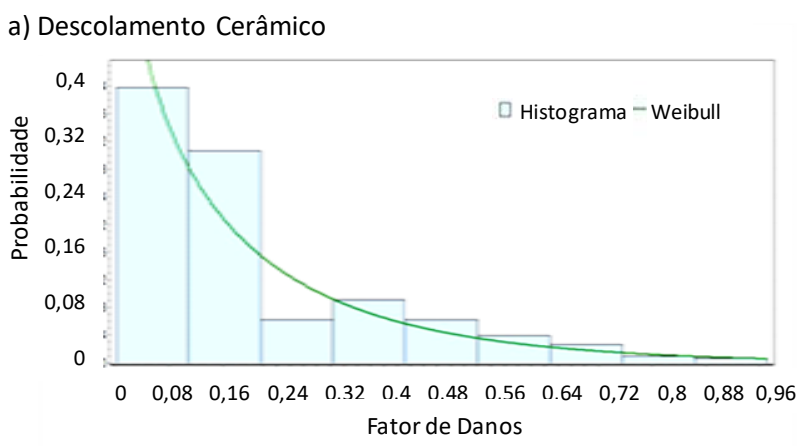

b) Fissuração
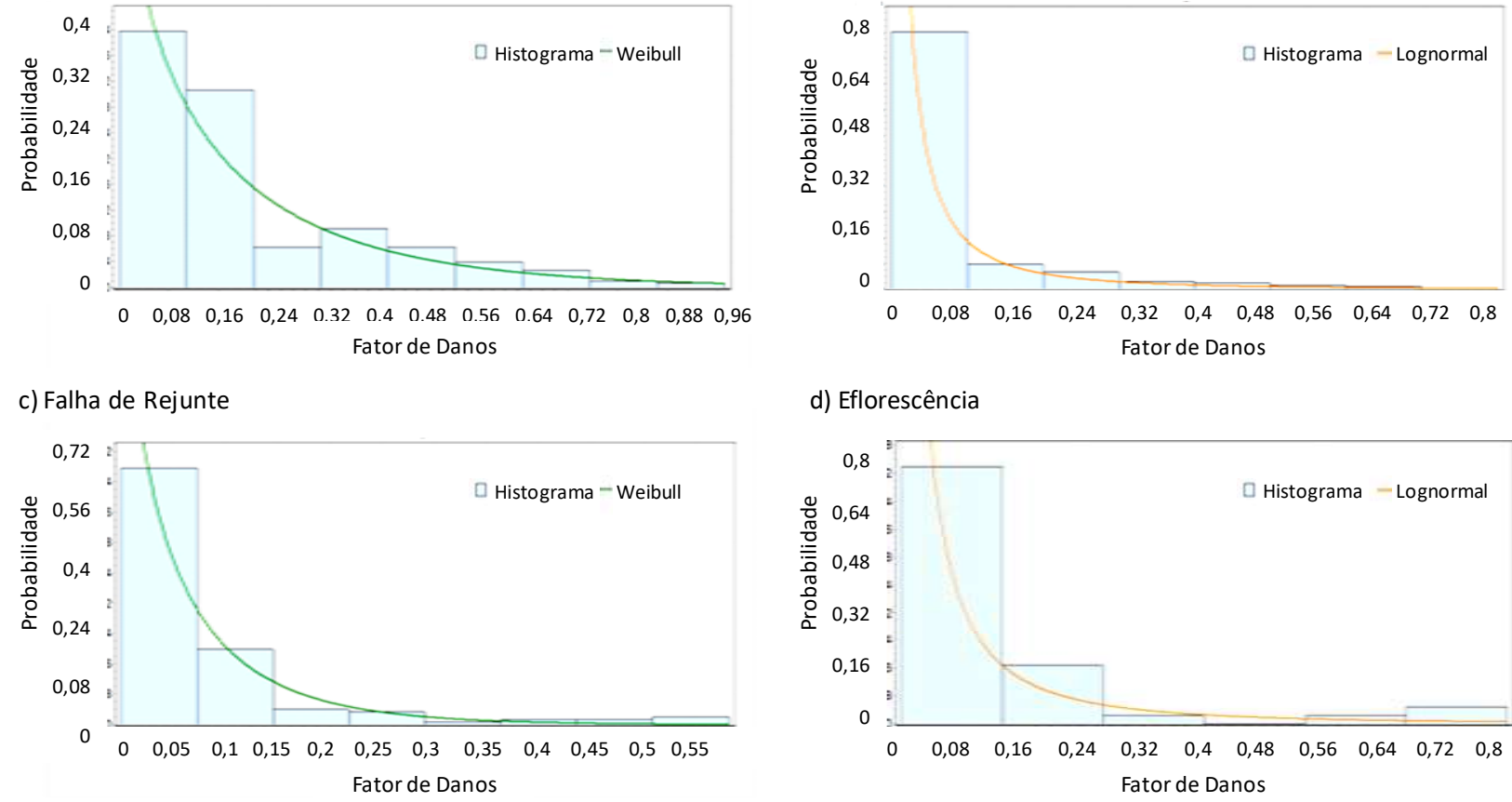

Figura 2 - Histograma e função de distribuição de probabilidade para cada anomalia

Para todas as anomalias consideradas, nota-se uma grande concentração de ocorrência de um nível baixo de degradação e à medida que esse nível aumenta, a concentração de casos no histograma diminui. Este fato indica um decrescimento de valores altos de degradação, assim resultando em uma curva com assimetria negativa. O mesmo comportamento é observado quando se trata da orientação da fachada. Considerando os valores do indicador de degradação FD, nota-se que as anomalias de eflorescência, falha de rejunte e fissuração são anomalias que apresentam uma maior concentração em níveis baixos de degradação. Enquanto que o descolamento cerâmico apresenta maior concentração tanto em níveis mais baixos quanto em niveis médios de degradação.

Em relação ao melhor ajuste de curvas de probabilidade, o descolamento cerâmico obteve melhor ajuste a uma distribuição Weibull e teve um erro quadrático médio (EQM) igual a 5,83E-05. A fissuração foi melhor ajustada a uma curva Lognormal e apresentou um EQM igual a 2,77E-07. A falha de rejunte foi ajustada a uma distribuição de Weibull com EQM igual a 3,14E-04. A eflorescência ajustou-se melhor a uma distribuição Lognormal e teve um EQM equivalente a2,56E-04. Os valores de EQM indicam um ajuste adequado das distribuições.

A probabilidade de obter um FD inferior a 0,05 é de aproximadamente $28 \%$ para descolamento cerâmico, $69 \%$ para fissuração, $55 \%$ para falha de rejunte e $59 \%$ para eflorescência. Isto indica que a probabilidade de ocorrer menores valores de FD de descolamento cerâmico é inferior as demais anomalias. Considerando um FD equivalente a 0,40 a probabilidade é de $15 \%$ para descolamento cerâmico e quase nulo para as demais anomalias. Isto indica que a probabilidade de ocorrer maiores valores de FD de descolamento cerâmico é superior as demais anomalias. Desta forma, as anomalias de descolamento cerâmico acontecem em maiores extenções que as demais anomalias. Uma vez que o descolamento cerâmico afeta brustamente o desempenho do sistema de revestimento cerâmico, fica evidente a necessidade de ações que evitem o surgimento desta anomalia.

\subsection{Probabilidade de degradação em relação à orientação}

Para a análise das orientações, os histogramas do Fator de Danos de cada anomalia foram obtidos conforme a orientação na qual a fachada está direcionada. Da mesma forma que que foi analisado as curvas das anomalias, foram testadas as curvas de probabilidade de Lognormal, Gumbel, Weibull, Normal e Exponencial para as orientações. A Figura 3 mostra os histogramas e as curvas de probabilidade de melhor ajuste para as orientações. 


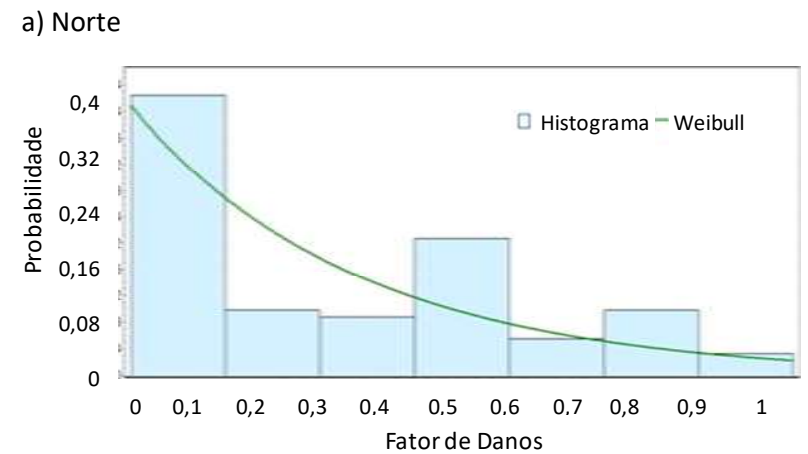

b) Sul
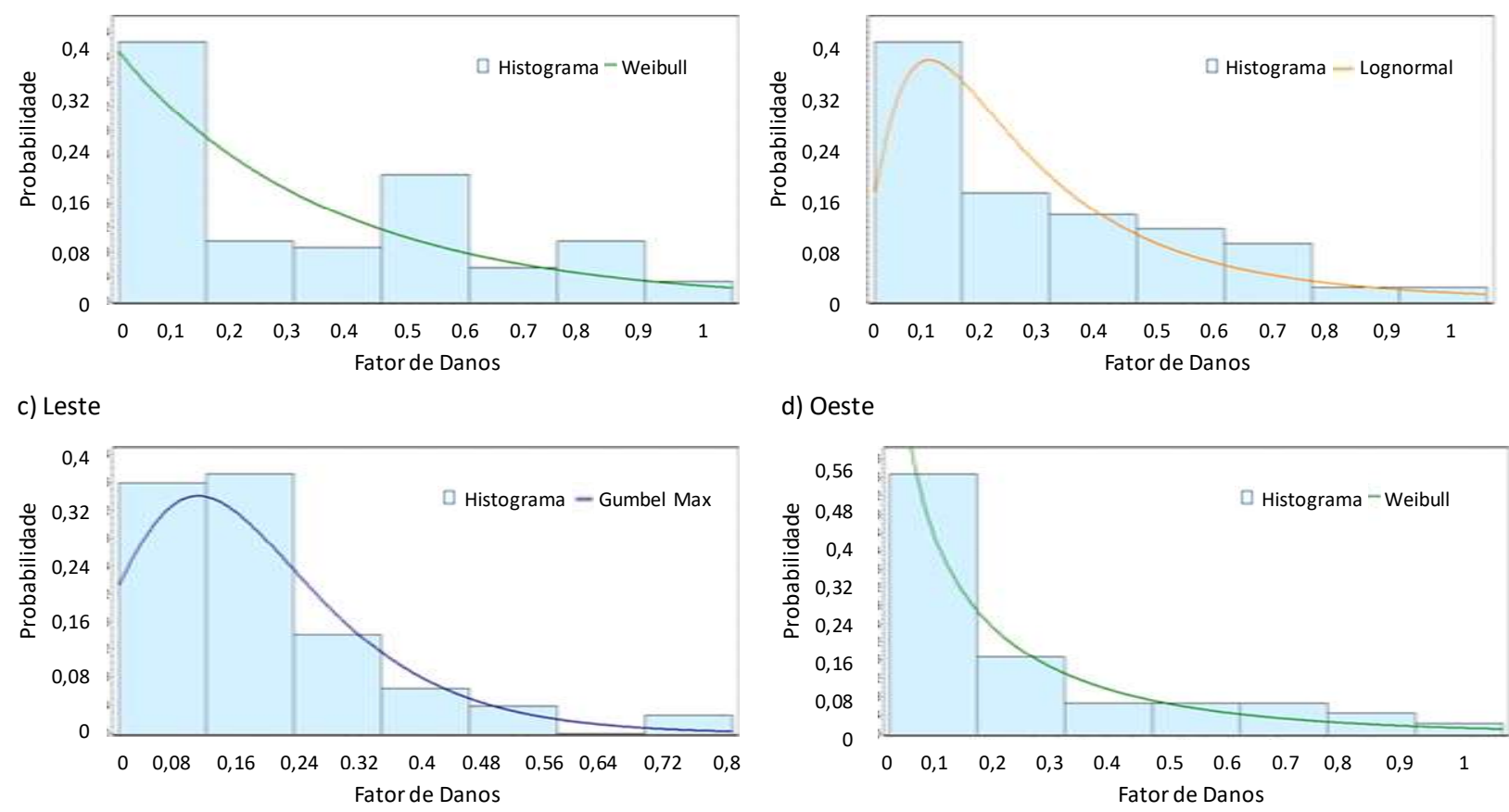

Figura 3 - Histograma e função de distribuição de probabilidade para cada orientação

Em relação ao melhor ajuste de curvas de probabilidade, a orientação norte foi a que obteve o melhor ajuste para uma distribuição Weibull e teve um erro quadrático médio (EQM) igual a 3,48E-04. A orientação sul foi melhor ajustada a uma curva Lognormal e apresentou um EQM igual a 1,85E-04. A orientaçãoleste foi ajustadaa uma distribuição de Gumbel Max com EQM igual a 1,58E-04. Já para a orientaçãooeste ajustou-se melhor a uma distribuição Weibull e teve um EQM equivalente a 5,05E-05. Os valores de EQM indicam um ajuste adequado das distribuições.

Observando as curvas de probabilidade na Figura 3, as orientações Norte, Sul e Leste apresentam propabilidade entre $31 \%$ e $43 \%$ de apresentar um FD igual a 0,10 . Já a orientação Oeste apresenta uma probabilidade superior a $50 \%$ de apresentar este valor de FD. Este fato indica que a orientação Oeste tende a degradar-se mais facilmente que as demais. Possivelmente, isso ocorre porque na região centro-oeste do Brasil a radiação solar e a chuva dirigida atingem com maior intensidade a fachada orientada para a direção Norte ao longo do ano, conforme afirmam Piazzarollo et al. (2019) e Baueret al. (2015). Considerando um valode de FD igual a 0,40, a probabilidade é similar a todas as orientações, variando entre $9 \%$ a 15\%.

O tempo é um fator determinante no fenômeno de degradação. Desta forma, para uma análise mais apurada, as fachadas foram separadas em dois grupos: com idade inferior e superior a 15 anos. Esse ajuste foi realizado para a anomalia de descolamento cerâmico devido a qualidade de ajuste apresentada. As demais anomalias não obtiveram resultados satisfatórios no teste de aderência. A Figura 4 ilustra os histogramas e as curvas de probabilidade de melhor ajuste para as orientações em função dos grupos de idade. 
a) Norte com idade inferior a 15 anos

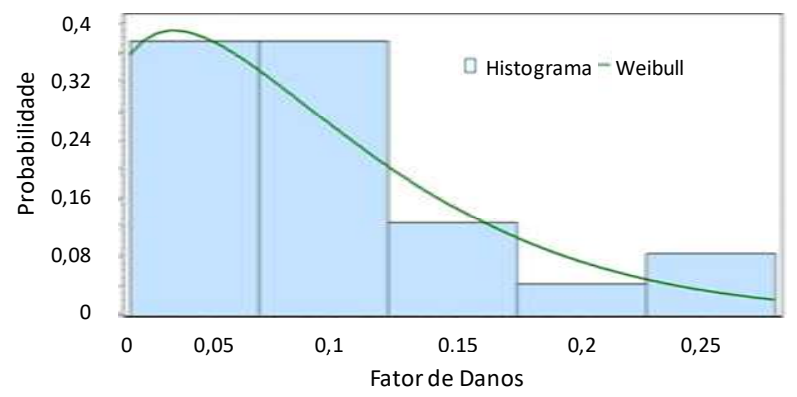

c) Sul com idade inferior a 15 anos

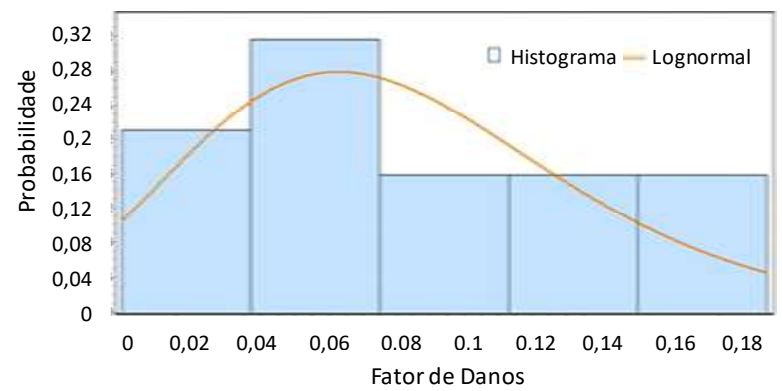

e) Leste com idade inferior a 15 anos

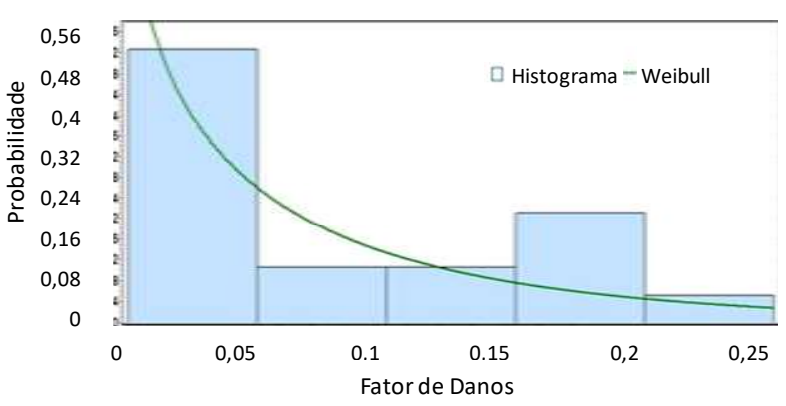

g) Oeste com idade inferior a 15 anos

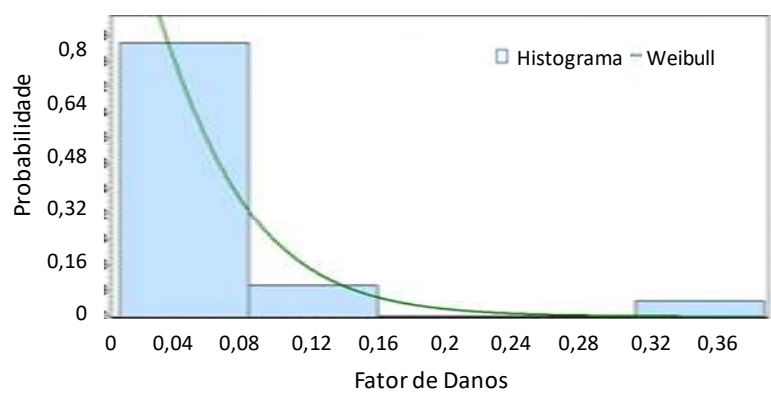

b) Norte com idade superior a 15 anos

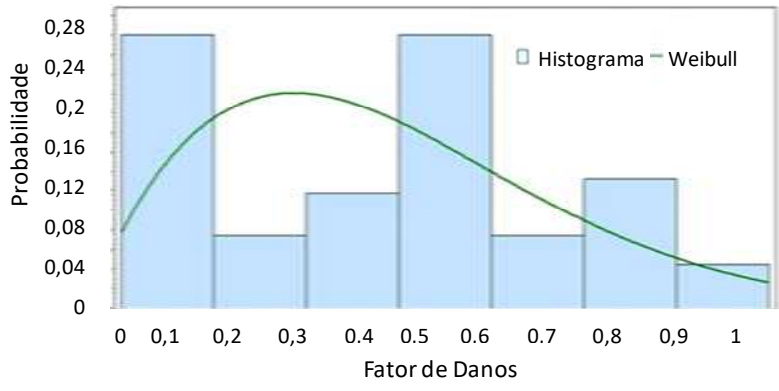

d) Sul com idade superior a 15 anos

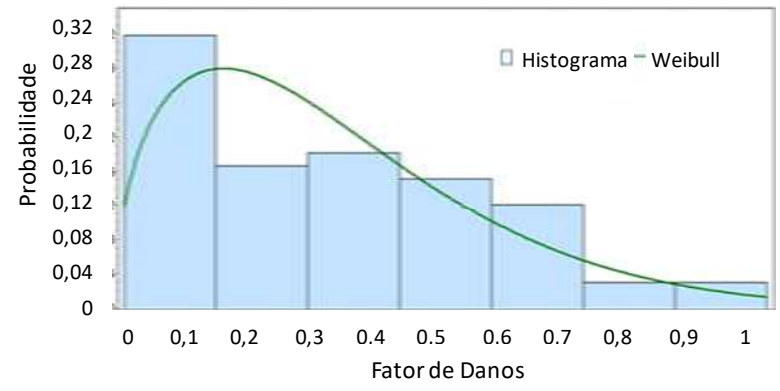

f) Leste com idade superior a 15 anos

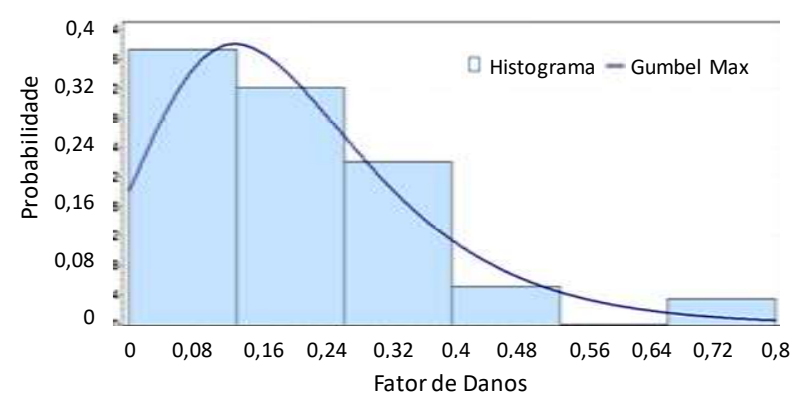

h) Oeste com idade superior a 15 anos

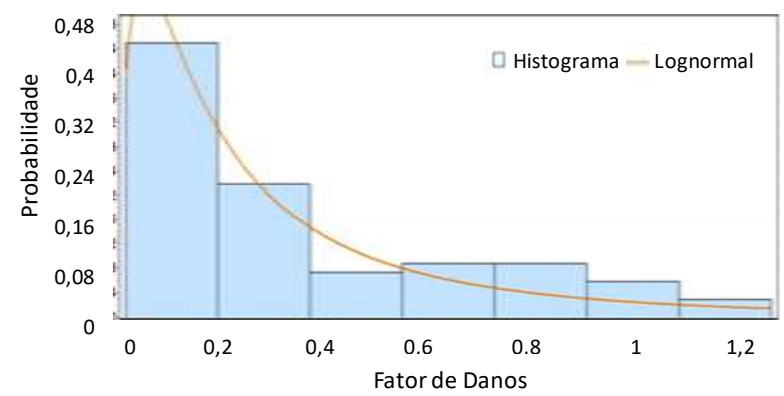

Figura 4 - Histograma e função de distribuição de probabilidade para cada orientação para os grupos de idade

A probabilidade máxima é representada pelo pico da curva. Assim sendo, nota-se que, em edifícios com idades inferiores a 15 anos (Figura 4a, 4c, 4e, 4g), os valores de maior probabilidade de FD equivale 0,03 para orientação norte, 0,07 para orientação sul, 0,01 para orientação leste e 0,01 para orientação oeste. Isto indica que em idades jovens as fachadas mais sucetiveis à degradação são as voltadas para o Sul. Embora o descolamento cerâmico seja uma anomalia resultande da variação dimensional provocada pela radiação solar, esta anomalia também pode surgir devido a presença de água no sistema. Desta forma, este resultado pode ser justificado pela presença de umidade no sistema no periodo chuvoso. Segundo Francinete et al. (2015), a orientação sul em edíficios localizados na região centro-oeste do Brasil recebem pouca radiação solar, assim prolongando o tempo de secagem das fachadas no período chuvoso.

Em edificios com idades superiores a 15 anos, observa-se que o pico da curva ocorre em valores de FD equivalente à 0,28 para orientação norte, 0,15 para orientação sul, 0,15 para orientação leste e 0,08 para 
orientação oeste. Isto indica que edifícioscom idades mais avançadas a orientação norte tende a degradarse mais facilmente que as demais. Este fato pode ser justificado pela ação dos agentes externos referente a radiação solar. A falha de adesão ao sistema de revestimento representada pelo descolamento cerâmico ocorre por fadiga (Uchôa, 2015). Desta forma, os descolamentos cerâmicos causados pela ação dos agentes externos de degradação referente à radiação solar tornam-se evidentes em longos períodos.

Os valores do pico, de maior probabilidade de ocorrência, corroboram com o esperado, ou seja, os edifícios mais velhos tendem a apresentar degradação maior que os edifícios mais novos.Um comportamento interessante a ser ressaltado é que o descolamento cerâmico apresenta valores relevantes mesmo em edifícios mais novos, o que possivelmente está relacionado a falhas de projeto ou de execução conforme apontado por Barros et al. (2018). Além disso, é importante a existência de um plano de manutenção, visto que a degradação tende a aumentar com o decorrer do tempo de exposição.

\section{Conclusões}

A degradação depende de vários fatores, principalmente da atuação dos agentes climáticos. Tendo isto em mente, é notável que a orientação da fachada influencia no processo de deterioração e na perda de desempenho do sistema de revestimento. A orientação da fachada que tem maior incidência do agente climático, tal como chuva e radiação solar, tende a sofrer uma maior degradação em relação as outras orientações.

Quando se utiliza o Fator de Danos para quantificar a influência de um determinado agente de degradação, não se deve desconsiderar os outros que também são intrínsecos e acarretam na deterioração da fachada. Apesar disso, percebe-se que pode ser feito uma correlação da orientação da fachada com a intensidade em que esta se degrada.

Naturalmente, a idade do edifício influencia no nível em que a fachada se encontra de degradação, sendo que os edifícios mais velhos são os mais afetados por esse processo, principalmente quando não há intervenções de mautenção. Consequentemente, os edifícios com idades mais avançadas demandam atenção especial e necessidade de plano de manutenção e caso seja necessário de revitalização.

Dentre as anomalias comum em sistema de revestimento cerâmico, a falha de adesão das placas cerâmicas a que tem maior tendência de surgir nas fachadas de edifícios. Esse comportamento não advém somente de agentes que atuam depois que o edifício já foi construído, mas também de erros de execução e na seleçãode materiais. Uma vez que a degradação dos edifícios é um tema complexo e com grandes questões a serem discutidas, ainda são necessárias novas pesquisas nessa área de conhecimento.

\section{Agradecimentos}

Os autores agradecem o apoio da Universidade de Brasília e da Universidade Estadual do NorteFluminense e a disponibilização das informações fornecidas pelo grupo de pesquisa do programa de pós graduação em estruturas e construção civil da Universidade de Brasília que investiga degradação em fachadas.

\section{Referências Bibliográficas}

Associação Brasileira de Normas Técnicas. ABNT NBR 15575-1 (2013): Edificações habitacionais Desempenho - Parte 1: Requisitos gerais. Rio de Janeiro.

ABNT NBR 15575-4 (2013): Edificações habitacionais - Desempenho - Parte 4: Sistemas de vedações verticais internas e externas - SVVIE. Rio de Janeiro.

Barros, H.E.B; Ferreira,D.S.F; Silva, A.F.P; Sousa, J.N. (2018). Análise dos Agentes de Degradação no Descolamento de Revestimentos Cerâmicos. 6a Conferência sobre Patologia e Reabilitação de Edifícios PATORREB 2018, Rio de Janeiro, Brasil; abril 2018. 
Bauer, E; Castro, E.K; Silva, M. N. B. (2015) Estimativa da degradação de fachadas com revestimento cerâmico: estudo de caso de edifícios de Brasília. Cerâmica, v.61, p.151-159.

Bauer, E; Piazzarollo, C. B; Souza, J. S; Dos Santos, D. G. (2020) Relative importance of pathologies in the severity of facade degradation. Journal of Building Patholgy and Rehabilitation.

Bordalo, R; de Brito, J.; Gaspar, P.L.; Silva, A. (2010) Abordagem a um modelo de previsão da vida útil de revestimentos cerâmicos aderentes. Teoria e Prática na Engenharia Civil. v. 16. Pp. 55-69

Flores-Colen, I; De Brito, J.; Freitas, V.P (2010) Discussion of criteria for prioritization of predictive maintenance of buildings facades: Survey of 30 expects. Journal of Performance of Constructed Facilities. v. 24. n.4. pp. 337-344.

Francinete, P. Jr.; Souza, J.S.; Zanoni, V.A.G.; Silva, M.N.B.; Bauer, E. (2015) Relação entre a degradação de fachadas e a incidência de chuva dirigida e temperatura - Estudo de caso para os edifícios de Brasília Brasil. XIII Congresso latino-Americano de Patologia da Construção - CONPAT 2015, Lisboa, Portugal.

Gaspar,P. L.; Brito, J. de. (2008) Quantifying environmental effects on cement-rendered facades: A comparison between different degradation indicators. Building and Environment, v. 43, p. 1818-1828.

International Organization for Standardization ISO 15686-1 (2011): Buildings - Service life planning. Part 1: General principles and framework, International Organization for Standardization.

Piazzarollo, C.B.; Souza, J.S.; Bauer, E. (2019) Aplicação do método de mensuração de degradação em revestimentos de fachadas. TECSIC. São Paulo, Brasil. pp. 1-5.

Silva, A; Brito, J; Gaspar, P. L. (2015) Stochastic Approach to the Factor Method: Durability of Rendered Facades. Journal of Materials in Civil Engineering.

Silva, M.N.B. (2014) Avaliação Quantitativa da Degradação e Vida Útil de Revestimentos de Fachada Aplicação ao caso de Brasília/DF. Tese de Doutoramento. Faculdade de Tecnologia, Universidade de Brasília, Brasil.

Silva, M. N. B.; Bauer, E.; Castro, E. K.; Zanoni, V. A. G. (2014) Distribuição de ocorrência de danos e patologias em fachadas de Brasília - Estudo de caso. In: I Simpósio de Argamassas e Soluções Térmicas de Revestimento, 2014, Coimbra. Actas do I Simpósio de Argamassas e Soluções Térmicas de Revestimento. Coimbra: ITeCons, 2014. p. 1-11.

Souza, J.S.; Silva, A.; de Brito, J.; Bauer, E. (2018) Analysis of the influencing factors of external wall ceramic claddings' service life regression techniques. Engineering Failure Analysis. v.83, pp. 141-155.

Souza, J. S. (2019) Impacto dos fatores de degradação sobre a vida útil de fachadas de edifícios. Tese de Doutoramento.Faculdade de Tecnologia, Universidade de Brasília, Brasil.

Uchôa, J.C.B (2015) Análise Numérica e Experimental da Fadiga Termomecânica em Argamassas Colantes no Sistema de Revestimento Cerâmico. Tese de Doutoramento. Faculdade de Tecnologia, Universidade de Brasília, Brasil. 